\title{
Is optics a separate discipline?
}

\author{
M. Soileau, James Pearson
}

M. J. Soileau, James E. Pearson, "Is optics a separate discipline?," Proc. SPIE 3190, Fifth International Topical Meeting on Education and Training in Optics, (8 December 1997); doi: 10.1117/12.294373

Event: Fifth International Topical Meeting on Education and Training in Optics, 1997, Delft, Netherlands 
Is optics a separate discipline?

\author{
M. J. Soileau, Director and Professor of ECE and Physics \\ Center for Research and Education in Optics and Lasers (CREOL) \\ University of Central Florida \\ P.O. Box 162700 \\ 4000 Central Florida Blvd. \\ Orlando, FL 32816-2700
}

James E. Pearson, Executive Director

SPIE_-The International Society for Optical Engineering

P.O. Box 10

Bellingham, WA 98227-0010

\begin{abstract}
The question posed by the title is important for how optics is taught and how research is funded for optical sciences and engineering. We think that the simple, correct answer to this question is "yes." This paper addresses this issue and suggests strategies for raising the profile of optics education at all levels.
\end{abstract}

Key Words: optics education, academic discipline, optical science and engineering, optoelectronics

Surely the practitioners of every technical science and subject at some time will claim that their subject is one of the fundamental building blocks of the universe of science, engineering, and technology. And the physicists of the world will usually smile benignly at the debate and try to end it quickly by saying something to the effect, "This is all well and good, but everything is part of physics. All this debate is just a confusion of this fundamental fact: all disciplines are merely subdisciplines of physics. Any effort to put one of these subdisciplines on the same status and plane with physics is merely to satisfy the egos of those who are too limited in their interests to see the larger picture."

There is an old story about two scientists (or engineers-one a student and one a professor) who were debating about which of their disciplines was the original. One claimed optics as her specialty; the other claimed acoustics for his. After much philosophical and empirical argument without either yielding to the other, they at last turned to cosmological and religious arguments, addressing the question: "where did God start when He created the universe?" Turning to the Bible, they examined the opening words of Genesis: In the beginning, the world was without form and darkness was upon it. And God said, "Let there be light." "Aha!" exclaimed the opticist (the professor), "There is the proof. God started the universe when He said, 'Let there be light'. Clearly light was the first physical phenomenon, and the basis on which God built the universe." "Ah, yes," said the acousticer (the student), "the evidence is clear, but your conclusion is wrong. Notice the Bible tells us, "And God said..."

But why has the realm of science and engineering and technology developed a structure (beyond "physics") with "separate", "independent" fields and disciplines, and even subdisciplines within many of these? Perhaps more importantly, and certainly more relevant to the purposes of this paper, why is the structure an important subject to examine? The answer, of course, is that the structure enables those who must deal with technical and business matters to handle the complexity and richness of the subject. Further, an appropriately chosen taxonomy of the physical/technical world can provide insights into interrelationships of the categories and subcategories, and provides a basis for organizing everything from education to industry projects, from research funding to technical staff organizations.

As when dealing with any complex set of interrelated items, the most elegant and efficient method is to find the "basis set" of "eigenfunctions" that enable a complete description of every subject, in the most compact way. As in mathematical representations, the members of this basis set are the minimum representation of the "universe," and all other subjects can be represented as some combination of these eigenfunctions. We claim that optics is an eigenfunction for organizing scientific and engineering research, education, and technology. 
The concept of optics as an igenfunction or basic vector is extended a bit further in Figure 1. That figure shows in a pictorial sense the way that optical science and engineering education is organized in three comprehensive optics programs in the USA-Center for Research and Education in Optics and Lasers (CREOL) at the University of Central Florida (UCF) ${ }^{2}$, Optical Science Center, University of Arizona ${ }^{3}$, and the Institute of Optics, University of Rochester ${ }^{4}$. The diagram is based upon a similar diagram provided by Professor Dennis Hall, Director of the Institute of Optics at the University of Rochester.

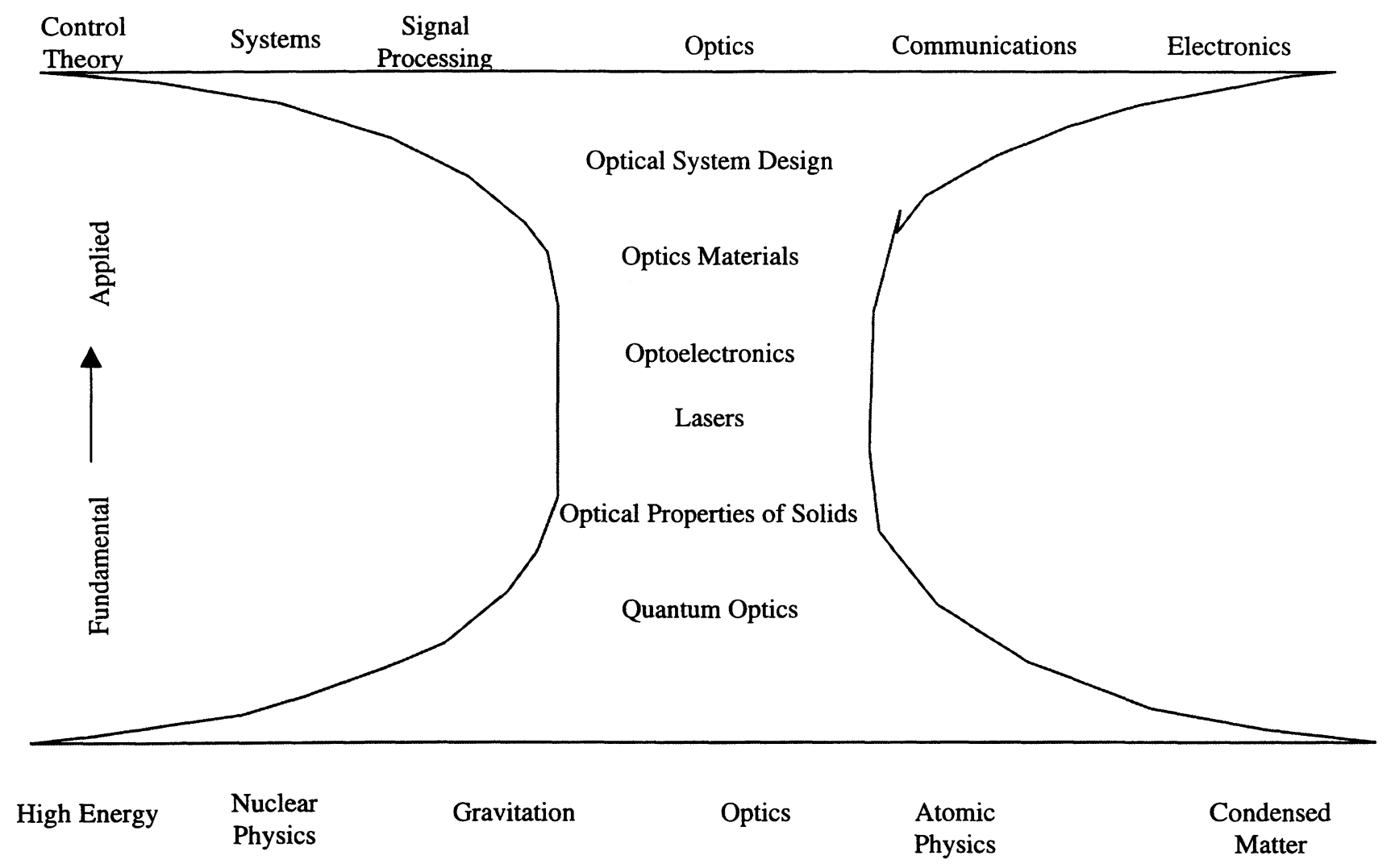

Figure 1. Academic Program Organized along the "other" axis

Figure 1 illustrates that the discipline of physics is typically organized around fundamental aspects of various branches of physics, e.g., nuclear, solid-state, optics, acoustics, etc. Electrical Engineering is typically organized along various applications of electro-magnetics, e.g., radar, communications, electronics, optics, signal processing, etc. By contrast, the OS\&E programs referenced are organized along the "other axis" or orthogonal to (but intersecting!) the physics and electrical engineering axes. Note that the wings of the "optics axis" are meant to show the relevance of optics to many other sub-fields of EE and physics. The basic idea of this arrangement is to provide students with a comprehensive education in optics that spans the fundamental physics of light generation and interaction with matter to the very applied areas of optical engineering.

It is a bit glib to say that there is a unique decomposition of the physical and intellectual world into "disciplines." The analogy to mathematical functions is imperfect, but it does illustrate an important point of this paper: as our knowledge of the physical world increases, and as new realizations of this knowledge emerge, it is important to periodically examine if 
we have organized the collection, distribution, and archiving of the information in the clearest, most efficient way. This is the equivalent in the technical world of what Thomas Jefferson said in regard to the socio-political world: "... laws and institutions must go hand in hand with the progress of the human mind, as that becomes more developed, more enlightened, as new discoveries are made, new truths discovered and manners and opinions change. With the change of circumstances, institutions must advance also to keep pace with the times."

The claim of this paper is that the times have changed: optics has now emerged as one of the "eigenfunctions", one of the basic discipline building blocks of the technical world. The world of science, engineering, and technology will be wellserved by recognizing this fact, and by establishing optics (or optical science and engineering) on a par with the other "basic" disciplines of physics, mechanical engineering, electrical engineering, acoustical engineering, civil engineering, chemistry, chemical engineering, etc. This will enable more efficient and rapid advancement of the science, engineering, and application of optics, which influences and enables an enormous variety of work in other disciplines.

It is currently difficult to locate information, people, products, companies, or activities related to optics simply because it is not a primary classification category. A few years ago, it was not possible to hire an "optical engineer" into the ranks of U.S., civil service, not because they did were in short supply, but because the government labor codes did not recognize the professional category. It has long been difficult, if not impossible, to get optical science projects funded by some agencies such as the U.S. National Science Foundation (NSF) because optics was viewed as "multidisciplinary", and did not align with the technical directorate structure (and thus funding categories and budget authorities) of NSF. This issue was addressed by an NSF-sponsored workshop' in 1994. After examining the many areas within the current NSF directorates that have Optical Science and Engineering (OS\&E) activities, the workshop committee concluded, "It is clear that OS\&E activities cut across the directorates and divisions and that they are a significant part of the programs within NSF. NSF, however, is organized in a vertical "stovepipe" structure that reflects the departmental organization of universities." But rather than take on the political issues with a bold step, the committee recommended that "NSF create an agency-wide, multi-disciplinary research initiative in Optical Science and Engineering." A similar recommendation was made for optoelectronics. At best this recommendation is a temporizing approach to a much bigger problem. It would be far better to recognize that optics is one of the fundamental disciplinary lines along which the NSF should organize its work, and thus establish an NSF optics (or optics and optoelectronics, or optical science and engineering) directorate.

Adding Optics to the primary categories for classifying technical work will clarify the organization of science and engineering. This is true whether it is literature, organizational structure, academic departments, or government technology funding. The current situation when optics is obscured or distributed in many pieces within physics, electrical engineering, materials, chemistry, etc., reminds one of the comment made by British astronomer Arthur Eddington: "In default of a better framework it [the Newtonian view of the world] was still used, but definitions were strained to purposes for which they were never intended. We were in the position of a librarian whose books were still being arranged according to a subject scheme drawn up a hundred years ago, trying to find the right place for books on Hollywood, the Air Force, and detective novels. ${ }^{7}$ [emphasis added]

First, let us deal with some terminology, recalling that Confucius has said, "The beginning of wisdom is to call things by their right name." It is important that the main points of this paper not be obscured by a debate over the choice of words for the discipline or field, particularly since there are many in use: optics, photonics, optoelectronics, electro-optics, imaging, opto-mechanics, electro-technology, and perhaps others. In discussing the many names applied to our field, Brian Thompson ${ }^{8}$ noted the following:

"We certainly have managed to create a maze of language to describe our field-a maze that seems as if specially designed to confuse and frustrate the uninitiated."

We choose to use "optics" or the phrase "optical science and engineering"as the defining term that encompasses the field, but the fundamental argument is the same: optics is a field of knowledge, research, engineering, and commerce that must be recognized as one of the primary structural elements when organizing science, technology, and economic markets.

Having chosen the term, "optics", for the purpose of defining the field or discipline, how is the discipline characterized to distinguish it from others? Since optics deals with light in all its forms, "doing things with light" will work, but is somewhat tautological. The "dictionary definition" we propose for the field and discipline of optics is as follows: 
"The field of optics encompasses the basic physical phenomena of, as well as the design and manufacture of devices for, the generation, transmission, collection, manipulation, and utilization of light; the physics of light-matter interactions; and the interpretation and utilization of information that is carried by light."

The term "Light" in this definition is intended to encompass the entire electromagnetic spectrum, even though "light" has been until recently been conventionally been used to refer to the near-infrared and shorter wavelength portions of the electromagnetic spectrum. Certainly this is the unique province of the field of optics, but at longer wavelengths there are subjects such as "microwave optics", and imaging at all wavelengths is appropriately within the realm of optics. Some may feel that since the photon is the elemental "particle" of light, in the above definition "photons" should replace "light" in the post-Dirac era. We think this is an irrelevant point, and inappropriately limits the definition of the field since the dual particle/wave nature of light is well established.

The above definition is very similar to that suggested by Professor Brian Thompson in his keynote address at the 1988 (first) International Conference on Education in Optics ${ }^{8}$.

“. . optical science and engineering has always meant the study of the generation, propagation, manipulation and detection of light, the interaction of light with matter, and its application to a variety of scientific, industrial, commercial and military applications, devices and systems."

Is this claim of "Optics is a separate and distinct technical Discipline" just a reflection of the ego needs of a few who have made optics the focus of their careers? Certainly not, but being good engineers and scientists, let's try to take an objective, analytical, logical, and quantitative look at the subject. First, we need to define some criteria or measures for a "fundamental field", or a "discipline" of science and engineering. The measures we feel are important are as follows:

- Uniqueness and fundamental nature

- Size

- Reach

- Impact

\section{Uniqueness and fundamental nature}

The Biblical starting point of the universe notwithstanding, light has long been recognized as one of the fundamental, cornerstone elements of the physical world. Most of the great pioneering physicists considered that understanding the nature of light was fundamental to understanding how the universe was put together and how it worked. Newton, Huygens, Foucault, Rayleigh, and many others examined many aspects of light, and even speculated on the corpuscular versus wave nature of light. These were some of the foundations on which Einstein built his great theories of the photoelectric effect (clearly an optical phenomenon) and the special and general theories of relativity. In fact, Einstein is quoted as frequently saying after the initial formulation of the General Theory of Relativity, "For the rest of my life I want to reflect on what light is." 10 The speed of light is not only a fundamental constant, but is a defining factor in understanding the nature of space and time. Many interactions at the most elemental level of nature are now understood to occur when light quanta (photons) are transmitted, absorbed, or exchanged.

It is only recently, within perhaps the last 35-40 years that the study of light has taken on a scope and magnitude that optics began to emerge as a comparable field from its genesis as a subset of physics. Before the mid-20" century, "optics" was commonly understood to mean the hardware of instruments such as eyeglasses, microscopes, telescopes, spectrometers, etc. -- items that have been in common use for at least 300 years. An "optical scientist" or "optical engineer" was someone who designed and built such instruments, but their fundamental training and discipline was most often physics, or chemistry, or one of the other "fundamental sciences." After photographic imaging was developed, optics became more than just an essential instrumentation in physics, chemistry, biology, and other branches of science. After the discovery of the laser, electrical engineering knowledge became increasingly important in optics, and more and more optics professionals obtained their primary degree in electrical engineering. 
The fundamental nature of light, and therefore the field of study that deals with light exclusively is thus well established. From the same arguments, it is also clear that there are subjects that are uniquely within the field of optics such as optical component and instrument (lenses, coatings, mirrors, filters, cameras, spectrometers, etc.) design and fabrication, image formation and analysis, phenomena, holography, and many others. There are also some that overlap with physics (e.g., lasers, nonlinear optics, etc.), some with electrical engineering (diode lasers, laser gyros, laser radars, flat panel and photoemissive displays, etc.).

\section{Body of identifiable professionals}

What does it take to define a discipline, or a profession? The basic requirements are: distinct scientific and engineering skills, which in turn define educational and degree programs with well-defined requirements; accreditation, certification, and possibly registration requirements; a substantial, and readily identifiable body of degreed professionals who possess the defined skills. On this latter point, there are organized technical professional societies in optics in nearly every country. In many of these countries, there is also at lest one optics trade association. Table 1 lists a sampling of these associations and the U.S.-based societies. The total number of professionals in the optics societies is growing each year. In 1996, neglecting overlap of membership, the membership is nearly 40,000 ; an estimate of the overlap gives $\sim 35,000$ for the total number of professionals in just this limited list. In addition to the companies who are members of the industry associations, there are over 620 companies who are corporate members of one or more of the societies.

\begin{tabular}{|c|c|}
\hline $\begin{array}{l}\text { INDUSTRY ASSOCIATION } \\
\text { (1995 Membership - companies) }\end{array}$ & $\frac{\underline{\text { SOCIETY }}}{(1996 \text { Membership - individuals) }}$ \\
\hline $\begin{array}{l}\text { Laser \& Electro-Optics Manufacturers } \\
\text { Association (LEOMA) - USA (42) }\end{array}$ & $\begin{array}{l}\text { SPIE - The International Society for } \\
\text { Optical Engineering }(12,000)\end{array}$ \\
\hline $\begin{array}{l}\text { Optoelectronics Industry Development } \\
\text { Association (OIDA) - USA (38) }\end{array}$ & $\begin{array}{l}\text { Optical Society of America } \\
(12,050)\end{array}$ \\
\hline $\begin{array}{c}\text { American Precision Optics Manufacturers } \\
\text { Association (APOMA) - USA (128) }\end{array}$ & $\begin{array}{c}\text { Lasers and Electro-Optics Society } \\
\text { of the IEEE }(7,000)\end{array}$ \\
\hline $\begin{array}{c}\text { Arizona Optics and Photonics Industry } \\
\text { Association (AOIA) - USA } \\
\end{array}$ & $\begin{array}{l}\text { Society for Imaging Science and Technology } \\
\qquad(2,000)\end{array}$ \\
\hline $\begin{array}{l}\text { Florida Electro-Optics and Photonics Industry } \\
\text { Association (FEOIA) - USA }\end{array}$ & $\begin{array}{c}\text { Laser Institute of America } \\
(1,650) \\
\end{array}$ \\
\hline $\begin{array}{c}\text { Connecticut Photonics Industry Cluster (CPIC) } \\
\text { - USA }\end{array}$ & $\begin{array}{l}\text { Society for Information Display } \\
(4,300)\end{array}$ \\
\hline $\begin{array}{l}\text { Scottish Optoelectronics Industries Association } \\
- \text { - Scotland }\end{array}$ & $\begin{array}{c}\text { European Optical Society } \\
\text { (17 national societies \& } 790 \text { individuals) }\end{array}$ \\
\hline $\begin{array}{l}\text { Optoelectronics Industry and Technology } \\
\text { Development Association (OITDA) - Japan }\end{array}$ & $\begin{array}{l}\text { International Commission on Optics } \\
\text { (43 territorial committees) }\end{array}$ \\
\hline $\begin{array}{c}\text { Chinese Optics \& Optoelectronic } \\
\text { Manufacturers Association (COEMA) - } \\
\text { China }\end{array}$ & $\begin{array}{c}\text { Japanese Optical Society } \\
\text { Japanese Laser Society } \\
\text { Chinese Optical Society } \\
\text { Australian Optical Society } \\
\text { • } \\
\text { • } \\
\text { • }\end{array}$ \\
\hline
\end{tabular}

Table 1. Industry and professional societies.

The membership numbers are from the records of the indicated organizations ${ }^{11}$. 


\section{Size of the optics field}

The number of companies and individuals active in associations and societies is one indicator of the size of the field. Another is the size of the economic markets. A recent study by the University of Connecticut ${ }^{12}$ identified over 4,300 individual optics/photonics companies in the United States. The markets ${ }^{13}$ served by optics technologies are growing rapidly, driven by a combination of laser, imaging, display, and image/signal processing technologies that enable new devices, instruments, and systems within markets ranging from healthcare to communications to aerospace. Depending on the definition of the "optics market" used, the total market in 1996 for optics products can be estimated anywhere in the range from $\$ 10 \mathrm{~B}$ to $\$ 100 \mathrm{~B}$. However, since optics is not a primary market and technical category, quantitative, reliable market data are not available. A significant point, however, is that the optics content is often the critical enabling technology for products at a higher level of system integration and application, even though the optics products may constitute only $1 \%$ to $30 \%$ of the value of the system-level product. The total actual market impact for optics is thus substantially larger when usage in other markets such as transportation, medicine, agriculture, communications, etc. is considered. As an example, the market for products enabled by optoelectronics ${ }^{14}$ alone has been estimated by the Optoelectronic Industries Development Association (OIDA) to be over $\$ 100$ Billion annually today, and is forecast to grow to over $\$ 460$ Billion by $2013^{15}$. Indeed, some estimates predict $21^{\text {st }}$ century optics markets as high as $10^{12}$ dollars per year! ${ }^{16}$ It is hard to find agreement in such estimates because it is difficult to agree on what should be counted. What is clear is that there are now large markets for optics-based products, that these markets are expanding, and that new products and markets are rapidly developing.

\begin{tabular}{|l|c|}
\hline \multicolumn{1}{|c|}{ ITEM } & $\underline{1996}$ \\
\hline & \\
Laser sales ${ }^{17}$ Optical and & $\$ 2.8 \mathrm{~B}$ \\
Optoelectronic component sales & $\sim \$ 200 \mathrm{M}$ (est) \\
$\begin{array}{l}\text { Number of companies listed in } \\
\text { commercial directories }\end{array}$ & LFW: 2,133 \\
& PS: 4,100 \\
$\begin{array}{l}\text { Institutions listed in SPIE's } \\
\text { "Education in Optics" directory }\end{array}$ & 223 \\
\hline
\end{tabular}

Table 2. Illustration of the size of the optics industry in 1996

\section{Impact and influence}

Because of the growing use of optics and light-based devices and systems, the $21^{\text {st }}$ century could easily become the "age of light". Optics is, for example, one of the key enablers of the information age, bringing broadband fibers, lasers, highresolution displays, small portable cameras, and a variety of other technologies that integrated with electronics become "optoelectronics". It is optoelectronics that enables visual information to be combined with audio and text data into the multimedia computers, CD-ROMs, and other information capture, storage, and delivery systems that are being increasingly used today in telecommunication networks.

Optical technologies continue to experience a high rate of development and innovation, but if the $21^{\text {st }}$ century does become the "age of light", it will be primarily because the use of optics is rapidly spreading into an increasing number of applications, often displacing mechanical and/or electrical technologies. It is hard to find an application where optics does not have a significant role. The range of applications includes all branches of scientific research, medicine, communications and information delivery, agriculture, transportation, defense, aerospace, education, entertainment, energy, environment, law enforcement, and many others. 
This increasing use of optics will fuel the growth of both the market for optical products, and for the product markets enabled by optics. In addition to the traditional products of optics -- eyeglasses, microscopes, telescopes, cameras, scientific instruments, etc. -- there are now lasers with average powers from a few microwatts for supermarket scanners to tens of kilowatts for cutting, welding, trimming, drilling, and marking; fiber optics for communications and a variety of sensors; medical devices such as computer-aided tomography (CAT), lasers for surgery, and imaging endoscopes and other devices for minimally-invasive surgery; lithography instruments for semiconductor manufacture; flat panel displays for computers and large screen applications; passive imaging and laser-guided systems for precision navigation, guidance, and smart-weapon control; imaging instruments for manufacturing inspection and quality control, and for machine and robot vision; optical sensors for temperature, pressure, strain, etc.; and many other products and applications too numerous to list. (Even public toilets utilize optics in their automatic flushing mechanisms!)

Some of the most exciting recent developments have been in the application of optics technology to manufacturing. The three broad categories of optical devices that are seeing increased utilization in manufacturing are lasers, imaging devices, and sensors. Lasers are now widely used in industries such as automotive manufacture to cut and weld materials. The advantages of laser processing include lower costs, easy reconfiguration for custom products, reduced scrap, and the possibility of working with a wide variety of materials. Imaging devices include non-contacting high-speed optical coordinate measuring systems, robot vision, and machine vision for control, automation, inspection, and other functions.

The reality of expanding applications and markets for optics-based products presents challenges and opportunities for education in optics. This issue was elegantly addressed by W. M. Steen ${ }^{19}$ in his 1996 Schawlow Address at a meeting of the Laser Institute of America. In that paper, Professor Steen systematically addressed new areas of knowledge and emphasis needed in many engineering disciplines made imperative by advancements in optical science and engineering and optics-based applications. The following highlights just a few points from Professor Steen's address.

\begin{tabular}{|l|l|}
\hline \multicolumn{1}{|c|}{ DISCIPLINE } & \multicolumn{1}{|c|}{ KNOWLEDGE NEEDED } \\
\hline Electrical Engineering & $\begin{array}{l}\text { fiber communications, laser emplifiers, CD technology, holographic } \\
\text { memories and WDM elements, etc. }\end{array}$ \\
\hline $\begin{array}{l}\text { Mechanical } \\
\text { Engineering }\end{array}$ & $\begin{array}{l}\text { interferometers, laser gyroscopes, laser cutting, machine vision, laser } \\
\text { processing, new alloy formation, polarization, etc. }\end{array}$ \\
\hline $\begin{array}{l}\text { Chemistry and } \\
\text { Chemical Engineering }\end{array}$ & $\begin{array}{l}\text { Raman spectroscopy, nonlinear spectroscopy, pico- and femto- second } \\
\text { sources, LIDAR, DIAL, fiber sensors, etc. }\end{array}$ \\
\hline Medicine & $\begin{array}{l}\text { fiber optics, imaging systems, spectroscopy, beam divergence, laser sources, } \\
\text {.. }\end{array}$ \\
\hline
\end{tabular}

Table 3. Excerpts from Professor Steen's Schawlow Address ${ }^{19}$

It is unlikely that each of these disciplines (and many others) will have optical faculty or other faculty capable of providing the needed understanding. This fact supports the establishment of optics departments or academic units which can offer the kinds of education in optics needed by various disciplines, and supports the conclusion that optics (or optical science and engineering) should be considered as a separate discipline. One commonly accepted definition of an academic discipline is: "A commonly accepted body of knowledge with broad applications in other disciplines."

We believe that there is ample evidence that optics fits within this definition. Recognition of optics (or optical science and engineering) as an academic discipline will raise the profile of our field, aid the establishment of more degree programs in optics, and add visibility and the means to meet the needs of other disciplines that need access to optics education. 
The above conclusion is by no means unanimously accepted. In fact, we have discussed this subject with participants of the 1997 Education in Optics Conference who have the opposite opinion. In fact, there is great variation among the nations of the world as to how academic programs and scientific programs are organized. Part of the disagreement is due to lack of a commonly accepted definition of a discipline. We gave one definition earlier in this paper. The definition given in the English dictionary compiled by Funk \& Wagnalls is ${ }^{20}$ : "The studies collectively embraced in a course of learning." The Academic Affairs administration of the University of Central Florida has an even simpler definition" : "A branch of learning." It is clear that optics would satisfy either of these definitions.

Professor Pierre Chavel ${ }^{22}$ argues that it is best not to consider optics as a discipline and that such a step could alienate "opticists" who consider themselves physicists, electrical engineers, etc. He argues that we should seek other ways to promote optics.

One such way is the formation of a Coalition for Photonics and Optics (CPO). The CPO consists of USA based societies and industrial associations dealing with optics. The International Committee on Optics (ICO) is an observer in the CPO. The CPO was set up to help promote optics in the USA, with the specific objective of distributing and helping to implement suggestions of a report (soon to be published) by the US Academy of Science on the subject of optical science and engineering. Persons or groups interested may contact James E. Pearson ${ }^{23}$

The committee of the leadership of the OSA and the SPIE (persons in the "presidential chain" and the executive directors) recommended yet another way to promote optics. This group has proposed the establishment of an academic Honor Society to recognize outstanding undergraduate and graduate students studying optics. The intent is that this Honor Society will be international in scope. Other organizations involved in optics are invited to join this effort. For details contact either of the authors of this paper.

\section{SUMMARY}

What we are advocating is not the creation of a new, empty category for professionals and for technical and economic information, but an addition to the current structure of categories. The impact of this addition, however, will be significant, and in some cases profound. It will certainly cause a rearrangement of current bodies of knowledge. It may also cause a restructuring of financial resources and of university academic department structures. The logic and advantages of such rearrangements is easily lost in the turf battles. What is needed is an objective, application of the logical and analytical skills that scientists and engineers rightly claim as a primary, and necessary, characteristic of their trade. For as a speaker in a recent meeting said, "There is no greater threat to discovery than that dread disease... Hardening of the Categories."

\section{REFERENCES}

'Professor Jack Gaskill, University of Arizona, USA.

${ }^{2}$ CREOL/UCF, P.O. Box 162700, 4000 Central Florida Blvd., Orlando, FL 32816-2700.

${ }^{3}$ Optical Sciences Center, University of Arizona, Tucson, AZ

${ }^{4}$ Institute of Optics, University of Rochester, 113 Wilmont Bldg., Rochester, NY 14627.

${ }^{5}$ Dennis G. Hall, Director, Institute of Optics, University of Rochester, Rochester, NY, private communication, 1996.

${ }^{6}$ Thomas Jefferson, in a letter to Samuel Kercheval, dated July 12, 1816. This quote is part of one in the Jefferson Memorial in Washington, DC in the United States.

${ }^{7}$ Arthur Eddington, Relativity, Eighth Annual Haldane Lecture, May 26, 1937, speaking about the effect of adding General Relativity changes to the currently accepted order of physics.

${ }^{8}$ Brian J. Thompson, "Education in Optics-Challenge at Hand," SPIE Vol. 278, 1988, International Conference on Education in Optics (1988), pp. 2-9. 
"'Optical Science and Engineering, New Directions and Opportunities in research and Education", Report on NSF Workshop held 23-24 May 1994, NSF Report \#95-34.

${ }^{10}$ Albert Einstein, Aufsätze und Vorträge über Physik und Erkenntnis-theorie, Braunschweig, 1961, p. 88.

${ }^{11} J$. E. Pearson, "Concept for an International Optics and Photonics Industry Association", presented at SPIE Annual meeting; Denver, CO; 6 Aug 1996.

${ }^{12}$ Database developed by David Young for CONNECT - The New England Alliance for Photonics Technology Development, managed by the University of Connecticut Photonics Research Center.

${ }^{13}$ Photonics Corporate Guide (PS), (Laurin Publishing Co., Pittsfield, MA, 1996) and Laser Focus World Buyers Guide (LFW), (PennWell Publishing, Nashua, NH, 1996).

${ }^{14}$ The U.S. Department of Commerce has defined "optoelectronics" as "all systems, equipment, or components which emit, modulate, transmit, and/or sense light or are dependent on the combination of optical and electronic devices." (From "Critical Technology Assessment of the U.S. Optoelectronics Industry", Feb., 1994, available from NTIS, pub. \#93182382)

${ }^{15}$ “Market Opportunities in Optoelectronics", internal report of Optoelectronics Industry Development Association (OIDA), 1993.

${ }^{16} \mathrm{M}$. J. Soileau, "Photonics for the Knowledge Age," Congress on Innovation and Technology for the $21^{\text {st }}$ Century, Porto, Portugal, March 20, 1995, O.D.D. Soares et al (eds.), Innovation and Technology - Strategies and Policies, 141-147. () 1997 Kluwer Academic Publishers. Printed in the Netherlands.

${ }^{17}$ Laser Focus World, January, 1997 issue.

${ }^{18}$ “Optics Education -- 1966”, a listing of optics programs worldwide. Available from SPIE, Bellingham, WA.

${ }^{19}$ W. M. Steen, Mechanical Engineering Department, The University of Liverpool, UK, Schawlow Address, October 1996, "It Works Better If You Turn It On," OLaser Institute of America, Orlando, FL, USA.

${ }^{20}$ Funk \& Wagnalls @ 1982, J. G. Ferguson Publishing Co., NY, NY.

${ }^{21}$ Dr. Beth Barnes, private communication, 1997.

${ }^{22}$ Professor Pierre Chavel, Address for SPIE Directory, 1997.

${ }^{23}$ Dr. James E. Pearson, SPIE-The International Society for Optical Engineering, P.O. Box 10, Bellingham, WA $98227-$ 0010.

${ }^{24}$ Panelist speaking in a workshop sponsored by the National Academy of Sciences and the American Association of Engineering Societies addressing “The Changing Nature of Engineering”, 12-13 May 1997, Washington, DC. 